\title{
THE IMPACTS OF PERCEIVED RISK AND RISK PROPENSITY ON FINANCIAL WELL-BEING: AN APPLICATION ON BANK EMPLOYEES
}

\section{DOI: 10.17261/Pressacademia.2018.941}

JEFA- V.-ISS.3-2018(10)-p.328-338

Ismail Atabay', Bayram Alamur², Aysegul Yildirim Kutbay ${ }^{3}$, Fatih Koc ${ }^{4}$, Fatih Karakas ${ }^{5}$

'Balıkesir University, Havran Vocational School, Havran, Balıkesir, Turkey. atabay@balikesir.edu.tr, ORCID: 0000-0001-8979-5548

${ }^{2}$ Balıkesir University, Havran Vocational School, Havran, Balıkesir, Turkey.

alamur bayram@hotmail.com, ORCID: 0000-0002-1364-5604

${ }^{3}$ Balıkesir University, Burhaniye School of Applied Sciences, Burhaniye, Balıkesir, Turkey.

aysegulyildirim@balikesir.edu.tr, ORCID: 0000-0002-3100-2928

${ }^{4}$ Kocaeli University, Kandıra Vocational School, Kandıra, Kocaeli, Turkey.

fatih.koc@kocaeli.edu.tr, ORCID: 0000-0002-4751-2340

${ }^{5}$ Balıkesir University, Kepsut Vocational School, Kepsut, Balıkesir, Turkey. fatih.karakas@balikesir.edu.tr, ORCID: 0000-0002-7982-8454

Date Received: August 1, 2018

Date Accepted: September 16, 2018

To cite this document

Atabay, I., Alamur, B., Kutbay Yildirim, A., Koc, F., Karakas, F. (2018). The impacts of perceived risk and risk propensity on financial well-being: an application on bank employees. Journal of Economics, Finance and Accounting (JEFA), V.5(3), p.328-338.

Permemant link to this document: http://doi.org/10.17261/Pressacademia.2018.941

Copyright: Published by PressAcademia and limited licenced re-use rights only.

\begin{abstract}
Purpose- This study seeks to determine the impact of perceived risk on risk propensity and the impact of both variables on financial well-being. Methodolgy- The questionnaire prepared by using the Perceived Risk and Risk Propensity scales obtained from the study of Hunjra et al. (2017) and the Financial Well Being adapted from the study of Norvilitis et al. (2003) was applied to 679 employees in banks operating in Balıkesir province and the results were analyzed and interpreted using SPSS 22 and AMOS package programs.

Findings- It has been determined in the research that the effect on the risk propensity of perceived risk is negative and meaningful and the effect of perceived risk on the existing financial condition and future financial situation expectancy dimensions of financial well-being determined to be in significant. It has been determined that the effecweeeeet of risk propensity on the existing financial condition and future financial situation expectancy dimensions of financial well-being is negative and meaningful. It has been also determined that the effect of the existing financial condition dimension of financial well-being on the future financial situation expectancy dimension of financial well-being positive and meaningful. Conclusion- As a result of there search, it is determined that individuals with high risk perception have a low risk propensity and those with high risk propensity will not see themselves very well financially, the expectation of the future financial situation of those who feel good financially in the current situation is also positive.
\end{abstract}

Keywords: Perceived risk, risk propensity, financial well-being, banking sector employees.

JEL Codes: I31, D19, G40

\section{ALGILANAN RISK, RISK EĞiLIMI VE FINANSAL IYI OLMA HALI ÜZERINDEKi ETKILERi: BANKA ÇALIŞANLARI} ÜZERINDE BIR UYGULAMA ${ }^{1}$

\section{ÖZET}

Amaç- Bu çalışma, algılanan riskin risk eğilimi üzerindeki ve her iki değişkenin de finansal iyi olma üzerindeki etkisini tespit etme amacını taşımaktadır.

Yöntem- Araştırmada Norvilitis vd.(2003)'ün çalışmasından uyarlanan Finansal lyi Olma Hali ile Hunjra vd.(2017)'nin çalışmasından alınan Algılanan Risk ve Risk Eğilimi ölçekleri kullanılarak oluşturulan anket formu, Balıkesir ilinde faaliyette bulunan bankalardaki 679 çalışan üzerinde uygulanmış, elde edilen sonuçlar SPSS 22 ve AMOS paket programları kullanılarak analiz edilip yorumlanmıştır.

Bulgular- Araştırmada algılanan riskin risk eğilimi üzerinde etkisinin negatif yönlü ve anlamlı olduğu tespit edilmiş, algılanan riskin finansal iyi olma halinin mevcut finansal durum ve gelecekteki finansal durum beklentisi boyutları üzerinde etkisinin ise anlamsız olduğu belirlenmiștir. Risk eğiliminin finansal iyi olma halinin mevcut finansal durum ve gelecekteki finansal durum beklentisi boyutları üzerinde etkisinin ise negatif yönlü ve

${ }^{1}$ Bu çalışma 24-25 Mayıs 2018 tarihlerinde İstanbul'da gerçekleştirilen “Global Business Research Congress "de sunulan bildirinin genişletilmiş halidir. Balıkesir Üniversitesi Bilimsel Araştırma Projeleri Birimi (BAP) tarafından desteklenmiştir. Teşekkür ederiz. 
anlamlı olduğu belirlenmiştir. Finansal iyi olma halinin mevcut finansal durum boyutunun finansal iyi olma halinin gelecekteki finansal durum beklentisi boyutu üzerinde etkisinin ise pozitif yönlü ve anlamlı olduğu tespit edilmiştir.

Sonuç- Araştırma sonucunda risk algısı yüksek olan bireylerin risk eğiliminin düşük olduğu, risk eğilimi yüksek olan bireylerin ise finansal olarak kendilerini çok iyi görmedikleri, mevcut durumda kendisini finansal açıdan iyi hissedenlerin geleceğe yönelik finansal durum beklentisinin de olumlu olduğu tespit edilmiştir.

Anahtar Kelimeler: Algılanan risk, risk eğilimi, finansal iyi olma hali, bankacılık sektörü çalışanları.

JEL Kodları: I31, D19, G40

\section{GíRiş}

Latince kökenli bir kelime olan ve Fransızca "risque" kelimesinden türeyen risk kavramını Türk Dil Kurumu "zarara uğrama tehlikesi" olarak tanımlamıştır (TDK, 2018). Buna karşın iş hayatında risk kavramı içine fırsatların da dahil edildiği bir yaklaşım söz konusudur. Risk, araştırmacılarca farklı şekillerde tanımlanmıştır. Short (1984) riski, bireylerin yaşamdaki herhangi bir olay ya da durum ile ilgili tehlike etkisini deneyimleme olasılı̆̆ olarak tanımlarken, Sjöberg (1991) bir olayın olma olasılı̆̆ının bu olayın olumsuz sonucunu artırması ve kişilerin olası durumlar üzerinde düşünerek en az negatif sonuç doğuracak seçeneğe yönelim olarak tanımlamıştır. Fıkırkoca (2003) ise riski, belirli bir zaman aralığında, hedeflenen sonuca ulaşamama, kayba ya da zarara uğrama olasılığı ile istenmeyen bir olayın, zararın, kaybın oluşma olasılığı ve oluşması durumunda yaratacağı olumsuz etkinin şiddeti olarak ifade etmektedir.

Ekonomik anlamda risk, iktisadi karar birimlerinin verecekleri kararlar sonucunda ortaya çıkacak getiriyi olumsuz etkileyebilecek olayların gerçekleşme olasılığı anlamına gelmektedir. Koç 'a (2012) göre, riskin en önemli iki unsuru; belirsizlik derecesi ve satın alma kararından doğabilecek sonuçlardır. İktisat, psikoloji ve istatistik gibi farklı disiplinlerde risk kavramı kazanma ve kaybetme olasılıklarını içerirken, tüketici davranışlarında sadece olumsuz davranışlar üzerinde durulmaktadır (Stone ve Grønhaug, 1993;Dholakia, 2001). Roszkowski ve Davey (2010), belirsizlik durumunda bir harekete geçme isteğini tanımlayan "risk toleransı", "risk kabulü", "risk iştahı", "risk tutumu", "risk profili" ve "risk eğilimi" gibi finansal terimleri ayırt etmeye ve belirlemeye güçlü bir intiyaç bulunduğunu ileri sürmektedir.

Algılama, kişilerin çevreden gelen uyarıcıları, kendileri için anlamlı bir dünya yaratacak şekilde yorumlamaları olarak tanımlanmaktadır (Karafakıoğlu,2005,s.92). Bir başka deyişle algılama, bireyin anlamlı bir dünya görüntüsü yaratmak için bilgi girdilerini seçme, organize etme ve yorumlama sürecidir (Kotler, 2000: 152).Risk algısı ise, kişilerin riskin ciddiyeti ve özellikleri hakkındaki sübjektif yargısıdır (Gürsoy vd., 2008: 21).

Yatırımcıların finansal ürün satın almadan önce ve sonra hissettikleri belirsizliğin derecesi olarak tanımlanabilen finansal risk algılaması, yatııım kararları üzerinde etkili olmaktadır. Yatıııcıların davranışlarının odak noktasını, finansal ürünlerle ilgili değerlendirmeleri ve seçme kararları oluşturur (Deniz ve Erciş, 2008: 302).

Yatırımcılar açısından yatırım kararları verilirken, gelecekteki belirsizlik nedeniyle bir tahmin ve öngörüde bulunularak risk alma söz konusudur. Yatırım kararı, beklentiler ve risk arasındaki çatışma sonucunda oluşan alternatifler değerlendirilerek alınır. Bu nedenle bireylerin riske bakış açısı, yatırım kararları üzerinde etkilidir. Rana vd. (2011) yaptıkları çalışmada, yatırımcının risk algısındaki azalmanın risk eğilimini arttırdığını ve yatırım davranışını etkilediğini belirtmişlerdir.

Yatırımcıların risk karşısındaki tutumları; demografik, sosyal ve ekonomik koşullara bağlı olarak zaman içinde değişebilmektedir. Diğer bir ifadeyle, bir yatırımcının risk-getiri tercihi statik değil, dinamiktir (Anbar ve Eker, 2009).

Risk eğilimi, Stewart Jr ve Roth (2001) tarafından bireyin risk alma veya riskten kaçınma şeklindeki karar anındaki eğilimi olarak tanımlanmış, yazarlar risk eğiliminin riskli karar alma sürecinde tek başına risk alma davranışına yol açmadığını ancak önemli bir özellik olarak kabul edildiğini de eklemişlerdir. Linnas'a (2012) göre risk eğilimi, bir kişinin kaybetme ihtimaline karşılık şansını değerlendirmek için ne kadar istekli olduğudur. Bireyin belirsiz sonuçlara sahip durumlarda nasıl devam edileceğine karar verirken risk alma veya riskten kaçınmaya yönelik genel eğilimi genellikle "risk eğilimi" olarak adlandırılan iki karşıt özelliktir. Sitkin ve Pablo (1992), karar alıcı bireyin düşük ya da yüksek risk içeren davranışı seçerken bireyin özelliklerinin, sorunun yapısının ve deneyim durumunun etkili olduğunu belirtmişlerdir. Benzer şekilde Saraç ve Kahyaoğlu'na (2011) göre de yatırımcıların risk seviyesine kişilik özellikleri, sosyo-ekonomik faktörler ve psikolojik faktörler etki etmektedir. Erdem (2001) girişimcilerin risk alma eğilimi üzerine yaptığı çalışmasında, bireysel özelliklerin, bireyin deneyiminin ve çevresel faktörlerin risk alma eğilimi üzerinde etkili olduğunu savunmuştur.

Literatürde finansal iyi olma hali kavramı, kişinin maddi durumu ile ilgili memnuniyet algısı olarak tanımlanmaktadır (Falahati ve Paim, 2011). Prawitz vd. (2006) finansal iyi olma halini, kişinin kendi finansal durumundan kaynaklanan refah veya stres seviyesinin ifade edilmesi olarak tanımlanmaktadır. Bu kavram; bireyin maddi ve manevi açıdan finansal durumunu nasıl algıladığı, yaşam standartlarını nasıl yükselteceği, kendini finansal açıdan nasıl güvende hissedeceği ve ihtiyaçlarını nasıl karşılayabileceği gibi konuları ön plana çıkarmaktadır (Taft vd., 2013).Finansal iyi olma hali; bireyin ekonomik, çevresel, sosyal, duygusal, bedensel 
yönlerinin olumlu yansımaları sonucunda oluşmaktadır. Bu bağlamda birey, tüm bu faktörlere dayanarak kendini finansal olarak iyi ya da kötü hissetmektedir (Kutbay vd. , 2017). Bu kavram, her ne kadar bireyin bir özelliği gibi görünse de finansal davranışlarının bir sonucu olarak ortaya çıkmaktadır (Kim , 2000). Saraç ve Kahyaoğlu'na (2011) göre, herhangi bir menkul kıymete ilişkin verilecek yatırım kararında göz önünde bulundurulması gereken iki temel kriter; yatırımın riski ve yatırımın beklenen getirisidir. Yatırımcılar aynı risk seviyesine sahip iki yatırım alternatifi arasından yüksek beklenen getiriye sahip olanı ya da aynı beklenen getiriye sahip yatırım alternatiflerinden düşük risk seviyesine sahip olanı seçme eğilimindedir. Buradan hareketle, birey alternatifler arasında seçim yapması sonucunda kendini finansal yönden iyi ya da kötü hissetmektedir. Yaptığı yatırım beklentileri doğrultusunda gelişirse birey kendini rahat ve refah içinde hissederken, yapılan yatırım olumsuz neticelendiğinde bireyin kendini stresli hissetmesi beklenecektir.

Sabri ve Falahati (2012) tarafından yapılan araştırmada bireylerin finansal davranış eğilimlerinin finansal iyi olma hali seviyesini etkileyeceğini ileri sürülmüştür. Bu çalışmaya göre; akılcı finansal davranışların bireyin finansal iyi olma hali seviyesini arttıracağını, buna karşın yanlış yönetilen finansal sürecin ise, bireyi kısa ve uzun vadede sorunlarla karşı karşıya bırakacağını bu durumunda bireyin finansal iyi hali seviyesini düşüreceğini tespit etmişlerdir.

Finansal iyi olma hali doğası gereği özneldir. Çünkü maddi yönden bireyin kendini nasıl gösterdiğinden ziyade, onun maddi yönünü nasıl algıladığına dayanır. Bu nedenle, aynı gelir düzeyindeki bireyler, kişisel tercihleri ve değerlerine bağı kalmaları sonucu finansal iyi olma hallerini farklı değerlendirebilirler. Bireyin finansal iyi olma halini nasıl algıladığı kapsamlı bir faktör listesinden etkilenir (Brüggen vd.,2017). Bunlar literatürde; cinsiyet, yaş, eğitim, medeni durum ve aile yapısı gibi kişisel demografik özellikler (Joo ve Grable, 2004;Malone vd., 2010); finansal bilgi ve etkinliği (Shim vd., 2009; Vosloo vd., 2014); para ya da borç gibi konulara yönelik finansal tutumlar (Norvilitis vd., 2003); materyalizm gibi finansal eğilimler, risk eğilimi ve risk alma isteği (Gutter ve Copur, 2011); bütçeleme, tasarruf ve zorlayıcı satın alma gibi alanlardaki finansal davranışlar (Joo ve Grable, 2004; Shim vd.,2009)olarak belirtilmektedir.

Gutter ve Fontes (2006), Grable ve Joo (2004), Grable, Lytton ve O'Neil (2004), Grable ve Lytton (1999a), gelir düzeyi ile finansal risk alma davranışı arasında pozitif ilişki tespit etmişlerdir. Mittal ve Vyas (2007), yatırım araçlarının tercihinde gelirin rolünü incelemişler ve düşük gelirli kişilerin vadeli mevduat gibi düşük riskli yatırım araçlarına yaptıklarını, hisse senedi, yatırım fonu gibi yatırım araçlarını tercih etmediklerini tespit etmişlerdir. Gelir düzeyi ile finansal iyi olma hali değişkenlerinin araştırıldığı çalışmalarda ise; gelir düzeyi yüksek olan bireylerin finansal iyi olma halleri gelir düzeyi düşük olan bireylerden anlamlı olarak yüksek çıkmıştır (Clarkv.d., 2008; Sunal, 2012).

Literatürde kadınların erkeklere göre daha az risk alma durumunda oldukları, kadınların erkeklere göre daha fazla riskten kaçındıkları, kadınların algılanan risk düzeylerinin erkeklerden daha yüksek olduğu belirlenmiştir (Hawley ve Fuji, 1993-1994; Grable ve Lytton, 1998; Jianakoplos ve Bernasek, 1998; Grable ve Joo, 2000; Olsen ve Cox, 2001; Dwyer vd., 2002; Grable vd., 2004; Watson ve McNaughton, 2007; Deo ve Sundar, 2015; Kannadhasan, 2015). Yaş ile risk alma davranışı arasındaki ilişkiyi belirlemeye yönelik çalışmalarda ise farklı sonuçlara ulaşılmış olup; yaş ile risk algısı arasında pozitif veya risk eğilimi arasında negatif ilişki tespit eden çalışmaların yanı sıra (Hawley ve Fuji,1993-1994; Bajtelsmith, 1999; Finke ve Huston, 2003; Hallahan vd., 2004; Bellante ve Gren, 2004; Hanna ve Lindamood, 2005; Dohmen vd., 2005; Jianakoplos ve Bernasek, 2006; Grable vd., 2006; Watson ve McNaughton, 2007), yaş ile risk algısı arasında negatif veya risk eğilimi arasında pozitif ilişki tespit eden çalışmalar (Wang ve Hanna, 1997; Grable ve Lytton, 1999b; Grable, 2000; Harrison vd., 2005)ve yaş ile risk alma davranışı arasındaki ilişkiyi önemsiz olarak tespit eden çalışmalar (Haliassos ve Bertaut, 1995; Sung ve Hanna, 1996; Grable ve Lytton, 1998; Yang , 2004) bulunmaktadır. Finansal yatırım kararları üzerinde etkili olan demografik faktörlerden bir diğeri olan medeni durum ile ilgili yapılan çalışmalarda ise, evli kişilerin bekarlara göre daha yüksek risk algısına ve daha düşük risk eğilimine sahip oldukları belirlenmiştir (Grable ve Lytton, 1998; Grable ve Joo, 2004; Yao ve Hanna, 2005).

Bu çalışma dört bölümden oluşmaktadır. Birinci bölümde algılanan risk, risk eğilimi ve finansal iyi olma hali kavramları kısaca açıklanmış ve literatür taramasına yer verilmiştir. Çalışmanın ikinci bölümünde çalışmanın amacı, kullanılan veri seti ve metodolojisi hakkında bilgi verilmiştir. Çalışmanın üçüncü kısmında araştırma bulguları ve veri analizlerine yer verilmiş olup, çalışmanın dördünce ve son bölümünde sonuçlar değerlendirilmiştir.

\section{ARAŞTIRMA}

\subsection{Araştırmanın Amacı}

Bu araştırmanın amacı algılanan riskin risk eğilimi üzerindeki etkisini ve algılanan risk ile risk eğiliminin de finansal iyi olma hali üzerindeki etkisini tespit etmektir.

Banka çalışanları, hizmet verdikleri müşterilerine yatırım kararlarında yol göstermekte ve onların yatırım kararları üzerinde etkili olmaktadırlar. Banka gibi yatırım olanaklarının geniş olduğu bir sektörde çalışan ve finansal bilgi seviyeleri ortalama toplum bireylerine göre daha yüksek olan banka çalışanlarının, kendi portföylerini oluştururken yaptıkları tercihler sonucunda kendilerini 
finansal yönden nasıl hissetmekte olduklarının ve algılanan risk ile risk eğilimlerinin tespit edilerek, bunların finansal iyi olma hali üzerindeki etkisini tespit etmek bu çalışmanın amacını oluşturmaktadır.

\subsection{Araştırmanın Hipotezleri ve Modeli}

Araştırmanın amacını ifade eden model Şekil-1'de sunulmuştur.

Şekil 1: Araştırmanın Modeli

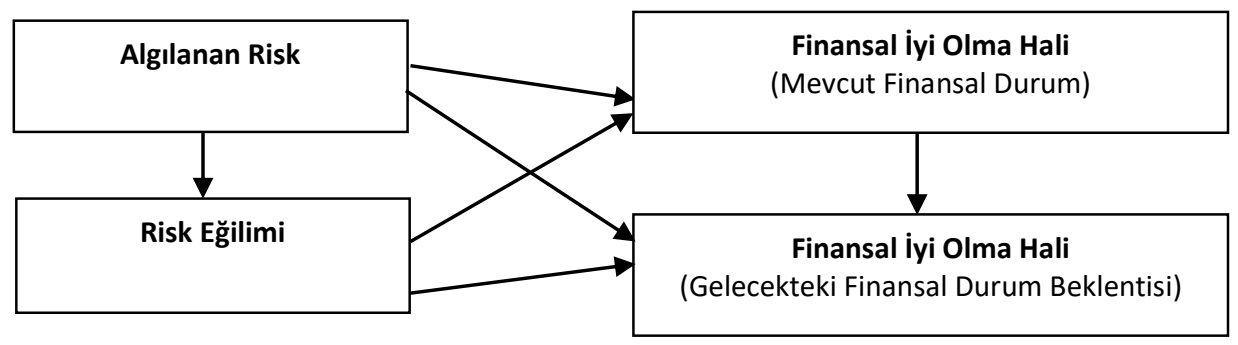

Araştırmanın modeline uygun olarak aşağıdaki hipotezler geliştirilmiştir.

H1: Algılanan Riskin Risk Eğilimi üzerinde anlamlı bir etkisi vardır.

H2: Algılanan Riskin Finansal İyi Olma Halinin Mevcut Finansal Durum boyutu üzerinde anlamlı bir etkisi vardır.

H3: Algılanan Riskin Finansal İyi Olma Halinin Gelecekteki Finansal Durum Beklentisi boyutu üzerinde anlamlı bir etkisi vardır.

H4: Risk Eğiliminin Finansal İyi Olma Halinin Mevcut Finansal Durum boyutu üzerinde anlamlı bir etkisi vardır.

H5: Risk Eğiliminin Finansal İyi Olma Halinin Gelecekteki Finansal Durum Beklentisi boyutu üzerinde anlamlı bir etkisi vardır.

H6: Finansal İyi Olma Halinin Mevcut Finansal Durum boyutunun Finansal İyi Olma Halinin Gelecekteki Finansal Durum Beklentisi boyutu üzerinde anlamlı bir etkisi vardır.

\subsection{Araştırmanın Sınırlılıkları}

Bu araştırma Balıkesir ilinde faaliyet gösteren bankalarda çalışanlar üzerinde yapılmış olup, ülkemizin diğer bölgelerindeki banka çalışanlarının zaman ve imkanlar nedeniyle araştırmaya dahil edilememiş olması bu araştırmanın kısıtlarını oluşturur.

\subsection{Araştırmanın Örneklemi}

Balıkesir ilinde faaliyet gösteren bankalarda çalışanlar bu araştırmanın ana kütlesini oluşturmaktadır. Anket uygulaması için kolayda örnekleme metodu seçilmiş ve uygulama yüz yüze yapılarak gerçekleştirilmiştir. Araştırma kapsamında araştırmaya katılmayı kabul eden716 banka çalışanı ile görüşülmüştür. Eksik bilgi verilen 37 anket araştırmaya dahil edilmeyerek, 679 anket veri analizinde kullanılmıştır.

\subsection{Araştırmada Kullanılan Veri Toplama Araçları ve Verilerin Analizi}

Araştırmanın değişkenlerinden Finansal İyi Olma Hali Ölçeği (FiHÖ) Norvilitis, Szablicki ve Wilso'nun (2003) yılındaki çalışmasından uyarlanmış olup 8 sorudan oluşmaktadır. Araştırmada, Hunjra, Qureshi ve Riaz (2017) tarafından literatürden uyarlanarak kullanılmış olan 4 sorudan oluşan Algılanan Risk Ölçeği (AR) ve 6 sorudan oluşan Risk Eğilimi Ölçeği (RE) kullanılmıştır.

Ölçeklerdeki ifadelerden her biri; (1) Kesinlikle Katılmıyorum , (2) Kısmen Katılmıyorum, (3) Kararsızım, (4) Kısmen Katılıyorum, (5) Tamamen Katılıyorum olmak üzere 5 basamaklı likert tipi puanlanmıştır. Ölçeklerdeki ters (reverse) ifadelere verilen cevaplar $5 \rightarrow 1,4 \rightarrow 2,3 \rightarrow 3,2 \rightarrow 4,1 \rightarrow 5$ olacak şekilde kodlanmıştır.

Verilerin analizinde SPSS 22 ve AMOS paket programları kullanılmıştır.

\section{ARAŞTIRMA BULGULARI VE VERILERIN ANALIZi}

\subsection{Demografik Faktörlere iliş̧kin Bulgular}

Aşağıdaki Tablo 1'de ankete katılan banka çalışanlarının demografik özelliklerini gösteren frekans dağılımları görülmektedir. 
Tablo 1: Demografik Özellikler

\begin{tabular}{|l|l|l|}
\hline Cinsiyet & Frekans & Yüzde \\
\hline Kadın & 329 & 48,5 \\
\hline Erkek & 350 & 51,5 \\
\hline Toplam & 679 & 100,0 \\
\hline Yaş & Frekans & Yüzde \\
\hline 25 ve Altı & 39 & 5,7 \\
\hline $26-30$ & 198 & 29,2 \\
\hline $31-35$ & 212 & 31,2 \\
\hline $36-40$ & 134 & 19,7 \\
\hline $41-45$ & 63 & 9,3 \\
\hline 46 ve Üstü & 33 & 4,9 \\
\hline Toplam & 679 & 100,0 \\
\hline
\end{tabular}

\begin{tabular}{|l|l|l|}
\hline Medeni Durum & Frekans & Yüzde \\
\hline Evli & 495 & 72,9 \\
\hline Bekar & 184 & 27,1 \\
\hline Toplam & 679 & 100,0 \\
\hline Öğrenim & Frekans & Yüzde \\
\hline Lise & 48 & 7,1 \\
\hline Ön Lisans & 99 & 14,6 \\
\hline Lisans & 493 & 72,6 \\
\hline Yüksek Lisans & 38 & 5,6 \\
\hline Doktora & 1 &, 1 \\
\hline Toplam & 679 & 100,0 \\
\hline & & \\
\hline
\end{tabular}

\begin{tabular}{|l|l|l|}
\hline Çalışılan Birim & Frekans & Yüzde \\
\hline Bireysel & 185 & 27,2 \\
\hline Kobi & 113 & 16,6 \\
\hline Müdür & 46 & 6,8 \\
\hline Operasyon & 335 & 49,3 \\
\hline Toplam & 679 & 100,0 \\
\hline $\begin{array}{l}\text { Çalışlan } \\
\text { Pozisyon }\end{array}$ & Frekans & Yüzde \\
\hline Müdür & 46 & 6,8 \\
\hline Yetkili & 452 & 66,6 \\
\hline Yönetmen & 181 & 26,7 \\
\hline Toplam & 679 & 100,0 \\
\hline & & \\
\hline
\end{tabular}

\subsection{Geçerlilik ve Güvenirlilik}

Araştırmada kullanılan ölçeklerin geçerlilikleri için açıklayıcı ve doğrulayıcı faktör analizleri yapılmıştır. Bunun yanı sıra, her ölçeğin AVE (AverageVarianceExtract) değerleri sunularak yakınsak (convergent) geçerliliğin var olup olmadığı araştırılmıştır. Güvenilirlik için, ölçeklerin Cronbach's Alpha ve CR (CompositeReliability) değerleri sunulmuştur.

\subsection{Araştırmada Kullanılan Öıçeklere İlişkin Açıklayııı ve Doğrulayıcı Faktör Analizleri}

Algılanan Risk Ölçeği, Risk Eğilimi Ölçeği ve Finansal İyi Olma Hali Ölçeği literatürde ele alınıp incelenmiştir. Birçok farklı ülkede ve farklı örneklem üzerinde ölçeğin geçerlilik ve güvenilirliği test edilmiştir. Bu noktada, ölçeğin bu çalışma için kullanılıp kullanılamayacağını belirlemek için önce Açıklayıcı Faktör Analizi (AFA), sonra da doğrulayıcı faktör analizi (DFA) yapılmıştır. Analiz sonuçları aşağıdaki Tablo-2'de sunulmuştur.

Yapılan Açıklayıcı Faktör Analizi (AFA) sonucunda, Finansal iyi Olma Hali ölçeğinin orijinal çalışma ile uyumlu olarak iki boyuttan oluştuğu, Risk Eğilimi ölçeğinin ve Algılanan Risk ölçeğinin ise yine orijinal çalışma ile uyumlu tek boyuttan oluştuğu görülmektedir. Faktörleri oluşturan her bir ifadenin faktör yükü 0,50'nin üzerindedir. Bu durum açıklayıcı faktör analizi için yeterli kabul edilmektedir (Hair vd. 2010). KMO ve Barlett değerleri incelendiğinde, KMO değerinin 0,811 ve Barlett testinin 0,001 düzeyinde anlamlı olduğu tespit edilmiştir. Ölçeğin boyutlarının güvenirliliğini belirlemek için her boyut için alfa katsayısı hesaplanmıştır. Boyutların alfa katsayılarının 0,70'ın üstünde olması yeterli derecede güvenirlilik koşulunun karşılandığını göstermektedir (İslamoğlu ve Alnıaçık, 2016). Özdeğeri 1'den büyük olan faktörler dikkate alınmıştır. Ölçeğin açıklanan toplam varyans değeri 59,630 olarak belirlenmiştir.

Ancak, bu sonucun doğrulanmasına ihtiyaç vardır. Bu nedenle, araştırmanın bu aşamasında Doğrulayıcı Faktör Analizi (DFA) yapılmıştır. Doğrulayıcı faktör analizi iki aşamada yapılmıştır. İlk aşamada, açıklayıcı faktör analizi sonucu elde edilen faktör yapısı, doğrulayıcı faktör analizi ile test edilmiştir. Bu analiz sonucunda elde edilen model uyum değerleri şu şekilde gerçekleşmiştir: $\mathrm{CMIN} / \mathrm{DF}=5,467 ; \mathrm{GFI}=0,893 ; \mathrm{CFI}=0,877 ; \mathrm{NFI}=0,855 ; \mathrm{RMR}=0,074 ; \mathrm{RMSEA}=0,081$. Bu değerler incelendiğinde, bazı değerlerin kabul edilebilir sınırın dışında olduğu görülmektedir. Bu nedenle bazı düzeltmeler yapılmıştır. Mevcut Finansal Durum (FiHÖ_Mev) ölçeğinden S8, Algılanan Risk (AR) ölçeğinden S10 ve Risk Eğilimi (RE) ölçeğinden S16 kodlu sorular düşük faktör yüküne sahip olduğu için ölçeklerden çıkarılmıştır. Mevcut Finansal Durum (FiHÖ_Mev) ölçeğinde, S1 ve S7 kodlu sorular arasında kovaryans çizilerek birleştirme yapılmıştır. Risk Eğilimi (RE) ölçeğinden S14 kodlu soru diğer faktörlerle yüksek varyans paylaşımı nedeniyle ölçekten çıkarılmıştır. Bunun sonucunda ortaya çıkan model uyum değerleri şu şekilde gerçekleşmiştir: CMIN/DF= 4,950; GFI= 0,930; $\mathrm{CFI}=0,925 ; \mathrm{NFI}=0,909 ; \mathrm{RMR}=0,070 ; \mathrm{RMSEA}=0,076$. Bu sonuçlara göre model uyum değerleri iyi uyum ve kabul edilebilir uyum düzeyindedir (Munro, 2005; Screiber vd. 2006; Şimşek, 2007; Hoopervd., 2008; Schumaker ve Lomax, 2010; Waltz vd., 2010) . Ayrıca ölçeklerin güvenirlilik (CR değerleri 0,70'in üzerinde olmalı) ve geçerlilik (AVE değerleri 0,50'nin üzerinde olmalı) düzeyleri istenilen seviyelerdedir (Hair vd., 2010; Gaskin, 2018). 
Tablo 2: Açıklayıcı ve Doğrulayıcı Faktör Analizi Sonuçları

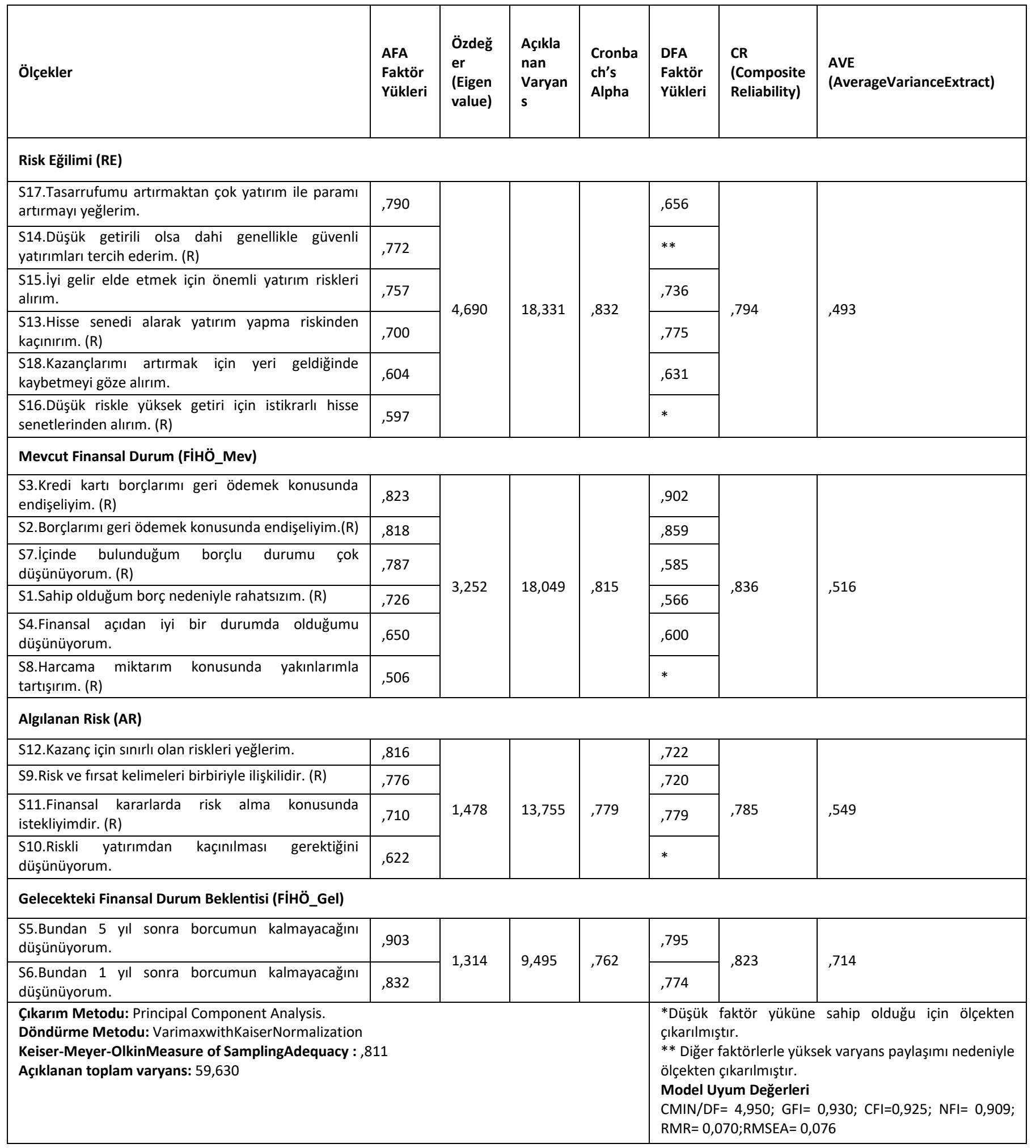


Diskriminant geçerlilik farklı yapılardaki her bir ilişkinin aralarındaki ilişkiyi ifade etmektedir (Fornell ve Larcker, 1981). Diskriminant geçerliliği ölçmek için Fornell ve Larcker (1981) kriteri kullanılmış olup, diskriminant geçerlilik değerleri Tablo 3'de verilmiştir. Bu tablo, değişkenler arasındaki ilişkileri ifade eden korelasyon katsayılarını ve değişkenlerin AVE değerlerinin kök dışına çıkmış hallerini (diyagonal bölümde koyu yazılmış sayılar) göstermektedir. Ayrışım geçerliliğinin sağlanması için, diyagonal bölümdeki sayıların tablo içerisindeki korelasyon katsayılarından büyük olması istenir. Tablodaki değerler incelendiğinde bu durumun gerçekleştiği görülmektedir.

Tablo 3: Fornell-Larcker Diskriminant Geçerliliği Tablosu

\begin{tabular}{|c|c|c|c|c|c|c|}
\hline & & & RE & FiHÖ_Mev & AR & FiHÖ_Gel \\
\hline Risk Eğilimi (RE) & & & 0,702 & & & \\
\hline Mevcut Finansal Durum & (FiHÖ_M & & $-0,150$ & 0,718 & & \\
\hline Algılanan Risk (AR) & & & $-0,677$ & 0,065 & 0,741 & \\
\hline $\begin{array}{l}\text { Gelecekteki Finansal } \\
\text { (FiHÖ_Gel) }\end{array}$ & Durum & Beklentisi & $-0,182$ & 0,302 & 0,095 & 0,845 \\
\hline
\end{tabular}

\subsection{Hipotezlerin Testi}

Araştırmanın modeline uygun olarak kurulan hipotezlerin test edilmesi için Yapısal Eşitlik Modellemesi yöntemi AMOS programı kullanılmıştır. Test sonuçları aşağıdaki Tablo 4'de sunulmuştur.

Tablo 4: Hipotezlerin Testi

\begin{tabular}{lcccccc}
\hline Değişkenler & & Beta & $\begin{array}{l}\text { Std. } \\
\text { Hata }\end{array}$ & $\begin{array}{l}\mathbf{t} \\
\text { değer } \\
\mathbf{i}\end{array}$ & $\mathbf{p}$ \\
\hline RE & $<---$ & AR & $-\mathbf{0 , 6 7 7}$ & $\mathbf{0 , 0 5 9}$ & $\mathbf{- 1 1 , 5 6 5}$ & $\mathbf{0 , 0 0 1}$ \\
FiHÖ_Mev & $<---$ & AR & $-0,066$ & 0,071 & $-0,937$ & 0,349 \\
FiHÖ_Mev & $<---$ & RE & $-\mathbf{0 , 1 9 3}$ & $\mathbf{0 , 0 7 1}$ & $\mathbf{- 2 , 6 9 5}$ & $\mathbf{0 , 0 0 7}$ \\
FiHÖ_Gel & $<---$ & AR & $-0,068$ & 0,125 & $-0,546$ & 0,585 \\
FiHÖ_Gel & $<---$ & M & $\mathbf{0 , 5 6 6}$ & $\mathbf{0 , 0 8 3}$ & $\mathbf{6 , 8 5 2}$ & $\mathbf{0 , 0 0 1}$ \\
FiHÖ_Gel & $<---$ & RE & $-\mathbf{0 , 3 2 6}$ & $\mathbf{0 , 1 2 6}$ & $\mathbf{- 2 , 5 8 6}$ & $\mathbf{0 , 0 1 0}$ \\
\hline Model Uyum Değerleri & & & & \\
\hline CMIN/DF & GFI & CFI & NFI & RMR & RMSEA \\
\hline 4,950 & 0,930 & 0,925 & 0,909 & 0,070 & 0,076 \\
\hline
\end{tabular}

Tablo 4'de yer alan sonuçlar incelendiğinde, algılanan riskin risk eğilimi üzerinde etkisinin negatif yönlü ve anlamlı olduğu tespit edilmiştir ( $\mathrm{H} 1$ : $\beta=-0,677 ; p<0,05)$. Dolayısıyla H1 hipotezi kabul edilmiştir. Bu bulgu, algılanan risk düzeyi yüksek olan bireylerin daha az risk alma eğiliminde olduklarını göstermekte olup, literatürdeki bulgularla (Rana vd., 2011) uyumludur. Algılanan riskin finansal iyi olma halinin mevcut finansal durum boyutu üzerinde ( $H 2$ : $\beta=-0,066 ; p>0,05)$ ve finansal iyi olma halinin gelecekteki finansal durum beklentisi boyutu üzerinde $(H 3: \beta=-0,068 ; p>0,05)$ etkisinin ise anlamsız olduğu belirlenmiştir. Bu durumda $H 2$ ve H3 hipotezleri reddedilmektedir.

Risk eğiliminin finansal iyi olma halinin mevcut finansal durum boyutu üzerinde ( $H 4: \beta=-0,193 ; p<0,05)$ ve finansal iyi olma halinin gelecekteki finansal durum beklentisi boyutu üzerinde ( $H 5$ : $\beta=-0,326 ; p<0,05)$ etkisinin negatif yönlü ve anlamlı olduğu belirlenmiştir. Bu durumda $\mathrm{H} 4$ ve $\mathrm{H} 5$ hipotezleri kabul edilmiştir. Bu bulgu risk eğilimi yüksek olanların finansal olarak kendilerini çok iyi görmediklerini göstermektedir. Bu durum; risk eğilimi yükseldikçe finansal açıdan beklentilerin de artması ve göreceli olarak bu bireylerin yüksek beklentilerine kıyasla kendilerini finansal açıdan yetersiz görmesi, tersine risk eğilimi düşük bireylerin finansal açıdan da yüksek bir beklentide olmayarak kendilerini finansal açıdan yeterli görmesi şeklinde açıklanabilir.

Finansal iyi olma halinin mevcut finansal durum boyutunun finansal iyi olma halinin gelecekteki finansal durum beklentisi boyutu üzerinde etkisinin pozitif yönlü ve anlamlı olduğu tespit edilmiştir (H6: $\beta=0,566 ; p<0,05)$. Bu durumda H6 hipotezi kabul edilmiştir. Bu durum mevcut durumda kendisini finansal açıdan iyi hissedenlerin geleceğe yönelik finansal durum beklentisinin de olumlu olduğunu göstermektedir. 
Çalışmada kullanılan değişkenler ile oluşturulan modele ilişkin sonuçların genel görünümü Şekil 2'de sunulmuştur.

\section{Şekil 2: Araştırmanın Modeline ilişkin Sonuçlar}

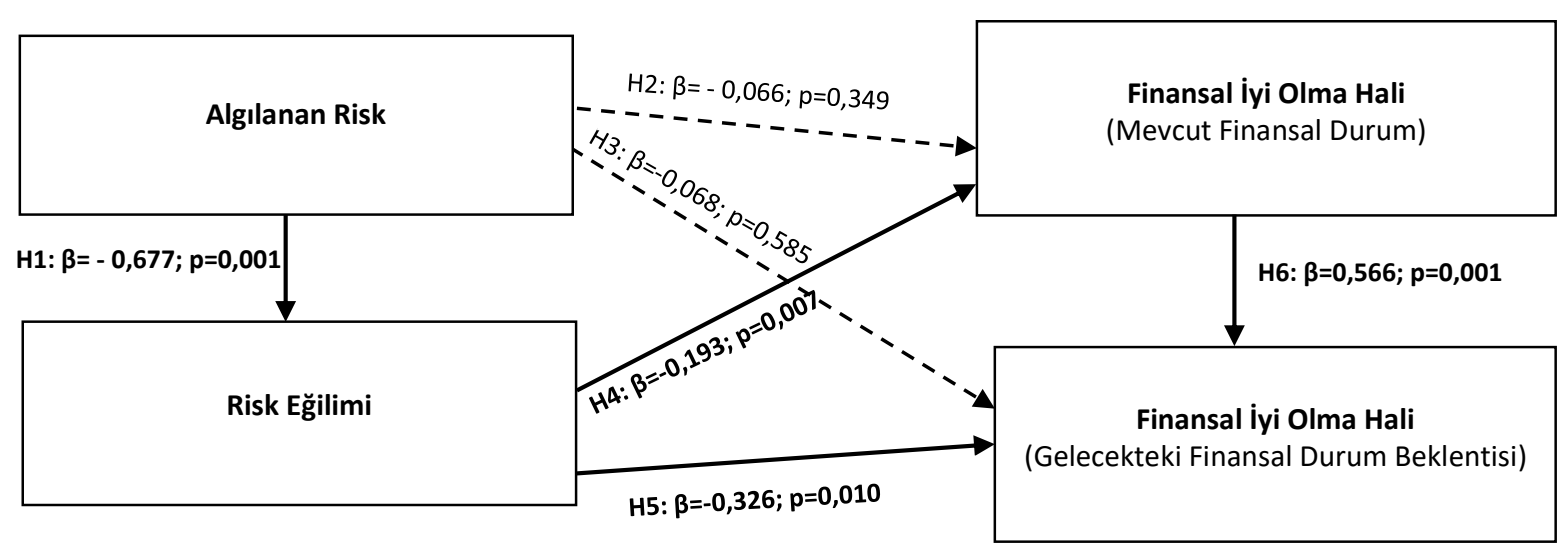

\section{SONUÇ}

Bu çalışma algılanan riskin risk eğilimi üzerindeki etkisini ve algılanan risk ile risk eğiliminin de finansal iyi olma hali üzerindeki etkisini tespit etme amacıyla yapılmıştır. Bu amaca ulaşmak için hazırlanan anket formu banka çalışanları üzerinde uygulanmıştır. Çalışmanın uygulama kısmının hizmet verdikleri müşterilerine yol göstererek yatırım kararları üzerinde etkili olan ve finansal bilgi seviyeleri ortalama toplum bireylerine göre daha yüksek olan banka çalışanları üzerinde yapılması çalışmaya ayrı bir önem katmakta ve literatüre katkı sağlayacağı düşünülmektedir.

Araştırma kapsamında oluşturulan hipotezler yapısal eşitlik modellemesi ile test edilmiştir. Araştırma sonuçlarına göre, algılan riskin risk eğilimi üzerinde negatif yönlü ve anlamlı bir etkisinin olduğu belirlenmiştir. Algılanan risk düzeyi yüksek olan bireyler daha az risk eğilimi göstermektedir. Yani bireylerin risk algısı yükseldikçe daha az risk alma eğilimi göstermekte, tersine risk algısı düştükçe de daha fazla risk alma eğilimi göstermektedirler.

Araştırmada algılanan riskin finansal iyi olma halinin mevcut finansal durum boyutu ve finansal iyi olma halinin gelecekteki finansal durum beklentisi boyutu üzerinde anlamlı bir etkisinin olmadığı belirlenmiştir. Risk eğiliminin ise finansal iyi olma halinin mevcut finansal durum boyutu ve finansal iyi olma halinin gelecekteki finansal durum beklentisi boyutu üzerinde negatif yönlü ve anlamlı bir etkisinin olduğu belirlenmiştir. Bu bulgu risk eğilimi yüksek olan bireylerin finansal olarak kendilerini çok iyi görmediklerini göstermektedir. Bu durum; risk eğilimi yükseldikçe finansal açıdan beklentilerin de artması ve göreceli olarak bu bireylerin yüksek beklentilerine kıyasla kendilerini finansal açıdan yetersiz görmesi, tersine risk eğilimi düşük bireylerin finansal açıdan da yüksek bir beklentide olmayarak kendilerini finansal açıdan yeterli görmesi şeklinde açıklanabilir.

Araştırmada finansal iyi olma halinin mevcut finansal durum boyutunun finansal iyi olma halinin gelecekteki finansal durum beklentisi boyutu üzerinde etkisinin pozitif yönlü ve anlamlı olduğu tespit edilmiştir. Bu durumda H6 hipotezi kabul edilmiştir. Bu durum mevcut durumda kendisini finansal açıdan iyi hissedenlerin geleceğe yönelik finansal durum beklentisinin de olumlu olduğunu göstermektedir.

Çalışmanın bazı kısıtları bulunmaktadır. Çalışmada verilerin bankacılık çalışanlarından elde edilmiş olması çalışmaya ayrı bir önem katmakla birlikte, aynı zamanda çalışmanın kısıtını da oluşturmaktadır. Ayrıca, verilerin sadece Balıkesir ilinde faaliyet gösteren bankalardaki çalışanlardan elde edilmiş olması da çalışmanın kısıtlarındandır. Gelecekte yapılacak çalışmalarda farklı sektör çalışanları üzerinde veya ülkemizin diğer bölgelerinde faaliyet gösteren banka çalışanları üzerinde de benzer araştırmaların yapılması araştırmacılara önerilmektedir. 


\section{KAYNAKÇA}

Anbar, A., Eker, M. (2012). Bireysel yatırımcıların finansal risk algılamalarını etkileyen demografik ve sosyoekonomik faktörler. ZKÜ Sosyal Bilimler Dergisi, 5(9), 129-150.

Bajtelsmit, V. L. (1999). Evidence of risk aversion in the health and retirement study. March 1, 1-18, http://www.aria.org/rts/proceedings/1999/risk_aversion.htm, (Erişim Tarihi: 13.05.2018).

Bellante, D., Green, C. A. (2004). Relative risk aversion among the elderly. Review of Financial Economics, 13(3), 269-281.

Brüggen , E., Hogreve, J., Holmlu, M., Kabadayi, S., Löfgren, M. (2017). Financial well-being: a conceptualization and research agenda. Journal of Business Research, 79, 228-237.

Clark, A., Frijters, P., Shields, M. (2008). Relative income, happiness, and utility: an explanation for the Easterlin paradox and other puzzles. Journal of Economic Literature aamerican Economic Association, 46(1), 95-144.

Deniz, A., Erciş, A. (2008). Kişilik özellikleri ile algılanan risk arasındaki ilişkilerin incelenmesi üzerine bir araştırma. Atatürk Üniversitesi İktisadi ve İdari Bilimler Fakültesi Dergisi, 22(2), 301-329.

Deo, M., Sundar, V. (2015). Gender difference: investment behavior and risk taking. SCMS Journal of Indian Management, 12(3), 74-81.

Dholakia, U. (2001). A motivational process model of product involvement and consumer risk perception. European Journal of marketing, 35 (11/12), 1340-1362.

Dohmen, T. J., Falk, A., Huffman, D., Sunde, U., Schupp, J., Wagner, G. G. (2005). Individual risk attitudes: new evidence from a large, representative, experimentally-validated survey. IZA Discussion Paper, No.1730, September.

Dwyer, P. D., Gilkeson, J. H., List, J. A. (2002). Gender differences in revealed risk taking: evidence from mutual fund investors. Economics Letters, 76(2), 151-158.

Erdem, F. (2001). Girişimcilerde risk alma eğilimi ve belirsizliğe tolerans ilişkisine kültürel yaklaşım. Akdeniz University Faculty of Economics \& Administrative Sciences Faculty Journal/Akdeniz Universitesi Iktisadi ve Idari Bilimler Fakultesi Dergisi, 1(2), 43-61.

Falahati , L., Paim, L. (2011). Gender differences in financial well-being among college students. Australian Journal of Basic and Applied Sciences, 5(9), 1765-1776.

Fıkırkoca, M. (2003). Bütünsel risk yönetimi. Ankara: Pozitif Matbaacılık.

Finke, M. S., Huston, S. J. (2003). The brighter side of financial risk: financial risk tolerance and wealth. Journal of Family and Economic Issues, 24(3), 233-256.

Fornell, C., Larcker, D. F. (1981). Structural equation models with unobservable variables and measurement error: algebra and statistics. Journal of Marketing Research, 382-388.

Gaskin, J. (2018). Confirmatory factor analysis. Gaskination's StatWiki, http://statwiki.kolobkreations.com, (Erişim Tarihi: 15.05.2018)

Grable, J. E., Lytton, R. H. (1998). Investor risk tolerance: testing the efficacy of demographics as differentiating and classifying factors. Financial Counseling and Planning, 9(1), 61-73.

Grable, J. E., Lytton, R. (1999a). Financial risk tolerance revisited: the development of a risk assessment instrument. Financial Services Review, $8(3), 163-181$.

Grable, J. E., Lytton, R. H. (1999b). Assessing financial risk tolerance: do demographic, socioeconomic and attitudinal factors work?. Family Relations and Human Development/Family Economics and Resource Management Biennial, 3, 1-9.

Grable, J. E. (2000). Financial risk tolerance and additional factors that affect risk taking in everyday money matters. Journal of Business and Psychology, 14(4), 625-630.

Grable, J. E., Joo, S. H. (2000). A cross-disciplinary examination of financial risk tolerance. Consumer Interests Annual, 46, $151-157$.

Grable , J. E., Joo, S. (2004). Environmental and biophysical factors associated with financial risk tolerancex. Journal of Financial Counseling and Planning, 15(1), 73-82.

Grable, J. E., Lytton, R., O'Neill, B. (2004). Projection bias and financial risk tolerance. The Journal of Behavioral Finance, 5(3), $142-147$.

Grable, J. E., Lytton, R. H., O'neill, B., Joo, S. H., Klock, D. (2006). Risk tolerance, projection bias, vividness and equity prices. The Journal of Investing, 15(2), 68-74.

Gutter, M., Fontes, A. (2006). Racial differences in risky asset ownership: a two-stage model of the investment decision-making process. Journal of Financial Counseling and Planning,, 17(2), 64-78.

Gutter, M., Copur, Z. (2011). Financial behaviors and financial well-being of college students: evidence from a national survey. Journal of Family and Economic Issues, 32(4), 699-714. 
Gürsoy, Ş. T., Çiçekçioğlu, M., Börekçi, N., Soyer, M. T., Öcek, Z. (2008). İzmir Karşıyaka Belediye çalışanlarında çevresel risk algılama düzeyi. Cumhuriyet Üniversitesi Tıp Fakültesi Dergisi, 30 (1), 20-27.

Hair, J., Black, W., Babin, B., Anderson, R. (2010). Multivariate data analysis (7. baskı b.). Pearson.

Hallahan, T. A., Faff, R. W., McKenzie, M. D. (2004). An empirical investigation of personal financial risk tolerance. Financial Services Review Greenwich-, 13(1), 57-78.

Haliassos, M., Bertaut, C. C. (1995). Why do so few hold stocks?. The Economic Journal, 105(432), 1110-1129.

Hanna, S. D., Lindamood, S. (2005). Risk tolerance of married couples. Proceeding of the Academy of Financial Services, October, 1-28.

Harrison, G. W., Lau, M. I., Rutström, E. E. (2007). Estimating risk attitudes in Denmark: a field experiment. The Scandinavian Journal of Economics, 109(2), 341-368.

Hawley, C. B. Fuji, E. T. (1993-1994). An empirical analysis of preferences for financial risk: further evidence on the Friedman-Savage model. Journal of Post Keynesian Economics, 16(2), 197-204.

Hunjra, A., Qureshi, Riaz, L. (2017). Psychological factors and investment decision making: a confirmatory factor analysis. Journal of Contemporary Management Sciences, 2(1), 65-82.

Hooper, D., Coughlan, J., Mullen, M. (2008). Structural equation modelling: guidelines for determining model fit. Articles, 2.

İslamoğlu, A. H., Alnıaçık, Ü. (2016). Sosyal bilimlerde araştırma yöntemleri. Genişletilmiş 5. Baskı, Beta Yayınevi.

Jianakoplos, N. A., Bernasek, A. (1998). Are women more risk averse?. Economic Inquiry, 36(4), 620-630.

Jianakoplos, N. A., Bernasek, A. (2006). Financial risk taking by age and birth cohort. Southern Economic Journal, 72(4), 981-1001.

Joo, S., Grable, J. (2004). An exploratory framework of the determinants of financial satisfaction. Journal of Family and Economic Issues, 25(1), 2550 .

Kannadhasan, M. (2015). Retail investors' financial risk tolerance and their risk-taking behaviour: the role of demographics as differentiating and classifying factors. IIMB Management Review, 27(3), 175-184.

Karafakıoglu, M. (2005). Pazarlama ilkeleri. Birinci Basım, Literatür Yayıncılık, İstanbul.

Kim, J. (2000). The effects of workplace financial education on personal finances and work. Unpublished doctoral dissertation. Virginia Polytechnic Institute and State: Blacksburg.

Koç, E. (2012). Tüketici davranışı ve pazarlama stratejileri: global ve yerel yaklaşım: pazarlama ve tüketici davranışı kavramlarının ingilizceleriyle. Seçkin Yayıncılık.

Kotler, P. (2000). Marketing management. New Jersey: Prentice Hall.

Kutbay, A., Özbek, V., Koç , F. (2017). Kişisel faktörler ve postmodern tüketim şekillerinin finansal iyi olma hali üzerindeki etkisi. In Proceedings of 2 nd International Conference on Scientific Cooperation for the Future in the Economics and Administrative Sciences , 262-273.

Linnas, A. (2012). Risk propensity of corporate financial executives: cross-country comparison. (Doctoral dissertation, Tartu Ülikool).

Malone, K., Stewart, S., Wilson, J., Korschi, P. (2010). Perceptions of financial well-being among American women in diverse families. Journal of Family and Economic Issues, 31(1), 63-81.

Mittal, M., Vyas, R. (2007). Demographics and investment choice among Indian investors. ICFAI Journal of Behavioural Finance, 4(2), 12-20.

Munro, B. H. (2005). Statistical methods for health care research (Vol. 1). Lippincott Williams \& Wilkins.

Norvilitis, J., Szablicki, B., Wilson, S. D. (2003). Factors influencing levels of credit-card debt in college students. Journal of Applied Social Psychology, 33(5), 935-94.

Olsen, R. A., Cox, C. M. (2001). The influence of gender on the perception and response to investment risk: the case of professional investors. The Journal of Psychology and Financial Markets, 2(1), 29-36.

Prawitz, A., Garman, E., Sorhaindo, B., O’Neill, B., Kim, J., Drentea, P. (2006). Incharge financial distress/ financial well-being scale: development, administration, and score interpretation. Financial Counseling and Planning, 17(1), 34-50.

Rana, M. H., Murtaza, S., Noor, F., Rehman, K. (2011). Effects of demographic factors on risky decision-making behaviour. European Journal of Social Sciences, 25(3), 69-76.

Roszkowski, M., Davey, G. (2010). Risk perception and risk tolerance changes attributable to the 2008 economic crisis: a subtle but critical difference. Journal of Financial Service Professionals, 64(4), 42-53.

Sabri, M., Falahati, L. (2012). Estimating a model of subjective financial well-being among college students. International Journal of Humanities and Social Science, 2(18), 191-199. 
Saraç, M., Kahyaoğlu, M. (2011). Bireysel yatırımcıların risk alma eğilimine etki eden sosyo-ekonomik ve demografik faktörlerin analizi. Journal of BRSA Banking \& Financial Markets,, 5(2), 135- 157.

Schreiber, J. B., Nora, A., Stage, F. K., Barlow, E. A., King, J. (2006). Reporting structural equation modeling and confirmatory factor analysis results: a review. The Journal of educational research, 99(6), 323-338.

Schumacker, R. E., Lomax, R. G. (2010). A beginners guide to structural equation modeling. New York: Routledge.

Shim, S., Xiao, J., Barber, B., Lyons, A. (2009). Pathways to life success: a conceptual model of financial well-being for young adults. Journal of Applied Developmental Psychology, 30(6), 708-723.

Short, J. (1984). The social fabric at risk: toward the social transformation of risk analysis. American Sociological Review, 49(6), 711-725.

Sitkin, S., Pablo, A. (1992). Reconceptualizing the determinants of risk behavior. Academy of Management Review, 17(1), 9-38.

Sjöberg, L. (1991). Risk perception by experts and the public. Center for Risk Research Stockholm School of Economics.

Stewart Jr, W., Roth, P. (2001). Risk propensity differences between entrepreneurs and managers: a meta-analytic review. Journal of Applied Psychology,, 86(1), 145-153.

Stone, R., Grønhaug, K. (1993). Perceived risk: further considerations for the marketing discipline. European Journal of marketing, 27(3), 39-50.

Sunal, O. (2012). Finansal iyilik hali ölçegi (FIHÖ): gecerlik ve güvenirlik calismasi/financial well-being scale (FWBS): a study of validity and reliability. Ege Akademik Bakis, 12(2), 209-214.

Sung, J., Hanna, S. (1996). Factors related to risk tolerance. Financial Counseling and Planning, 7, 11-19.

Şimşek, Ö. F. (2007). Yapısal eşitlik modellemesine giriş: temel ilkeler ve LISREL uygulamaları. Ekinoks.

Taft , M., Hosein, Z., Mehrizi, S., Rosha, A. (2013). The relation between financial literacy, financial wellbeing and financial concerns. International Journal of Business and Management, 8(11), 63-75.

TDK (2018). Genel Türkçe Sözlük. Türk Dil Kurumu, http://www.tdk.gov.tr/index.php?option=com gts, (Erişim Tarihi: 17.05.2018).

Vosloo, W., Fouche, J., Barnard, J. (2014). The relationship between financial efficacy, satisfaction with remuneration and personal financial wellbeing. International Business and Economics Research Journal, 13(6), 1455-1470.

Waltz C. F., Strickland O. L., Lenz E. R. (Eds.). (2010). Measurement in nursing and health research. Springer Publishing Company.

Wang, H., Hanna, S. D. (1997). Does risk tolerance decrease with age?. Financial Counseling and Planning, 8(2), 27-31.

Watson, J., McNaughton, M. (2007). Gender differences in risk aversion and expected retirement benefits. Financial Analysts Journal, 63(4), 5262.

Yang, Y. (2004). Measuring risk preferences: re-examination of Grable \& Lytton's 13-item questionnaire. Consumer Interests Annual, 50(2), 119122.

Yao, R., Hanna, S. D. (2005). The effect of gender and marital status on financial risk tolerance. Journal of Personal Finance, 4(1), 66-85. 